\title{
A comparative study of the estimators for the demand of Engineering Courses in Portugal
}

\author{
Raquel Oliveira, A. Manuela Gonçalves, and Rosa M. Vasconcelos
}

\begin{abstract}
For the purpose of modeling the demand of Engineering Courses in Portugal we analyzed the possible regression models for panel count data models by establishing a comparison between the estimators obtained and then finding the most appropriate ones for our dataset. A precise quantification of the demand for each academic program is facilitated by the rules of access to higher education, in National Contest for Access and Admission to Higher Education, where candidates must list up to six preferences of institution and program. The data used in this paper covers the results of the national contest from 1997 to 2015 provided by the Portuguese Ministry of Education and Science. Multivariate methodologies were performed in order to allow a better understanding of the students' allocation behavior. The results seem to indicate that the negative binomial estimates fit better the dataset analyzed.
\end{abstract}

\section{Introduction}

The idea of creating a European Higher Education Area (EHEA) was shared for the first time in the 800th anniversary of the University of Paris, Sorbonne Joint Declaration, in 1998 and was signed by the ministers of four countries: France, Germany, UK and Italy [1].

Raquel Oliveira

University of Minho, CMAT - Centre of Mathematics, Portugal, IPCA-EST, e-mail: rmro_17@hotmail.com

A. Manuela Gonçalves

University of Minho, CMAT - Centre of Mathematics, DMA - Department of Mathematics and Applications, Portugal, e-mail: nmneves@math.uminho.pt

Rosa M. Vasconcelos

University of Minho, 2C2T - Centre for Textile Science and Technology, DET - Department of Textile Engineering, Portugal, e-mail: rosa@ det.uminho.pt 
The decision to formalize this idea occurred one year later in Bologna, by 29-30 countries who expressed their willingness to commit to increasing the competitiveness of EHEA through the 1999 Bologna Declaration [2], highlighting the need to further the independence and autonomy of all Institutions of Higher Education (IHE). These steps were followed by Ministerial Conferences in Prague in 2001, in Berlin in 2003, in Bergen in 2005, in London in 2007, in Leuven/Louvain-la-Neuve in 2009, in Budapest-Vienna in 2010, in Bucharest in 2012, and in Yerevan in 2015.

The aim of the Bologna Process (BP) was to "strengthen the competitiveness and attractiveness of European higher education and to foster student mobility and employability through the introduction of a system based on undergraduate and postgraduate studies with easily readable programs and degrees. Quality assurance has played an important role from the outset too" [3].

The Ministerial Conferences above mentioned, provided more precise tools for implementing BP, such as modifying the structure of the undergraduate/postgraduate degrees, into a three-cycle system including the concept of qualifications frameworks, with an emphasis on learning outcomes, and introducing the concept of the social dimension of higher education and the recognition of qualifications as central to the European higher education policies. In Portugal, the first steps for BP implementation were given in 2005 by means of laws:

- $\mathrm{nr} 42 / 2005$ which defines the regulatory instruments for the creation of the European Area of Higher Education. This law regulates the structure of the cycles of studies, the comparability of the degree structure, further to a comparable degree structure, the creation of a system of academic credits, whose accumulation and transferability across countries is guaranteed; this law also defines the mobility of students during and after their graduation;

- $\mathrm{nr} 49 / 2005$, consisting of an amendment to the Law of the Education System Bases, including new areas and objectives of university education and polytechnic education.

Only in 2006, with decree $\mathrm{nr} 74 / 2006$, changes were made to the existing law of the educational system bases that enable BP implementation, particularly the adoption of a new degree structure based on three cycles: the first cycle is bachelor degree (licenciatura - L), with a normal duration of three years, the second cycle is master (mestrado - M), with a normal duration of one-half or two years, and the third cycle is doctorate (doutoramento). The universities were also given the opportunity to offer a combined degree called integrated master (mestrado integrado - MI), with a duration of 5 or 6 years [4].

As part of the reorganization and rationalization of the European higher education system [5], BP implementation in Portugal was carried out by the Portuguese Ministry of Science Technology and Higher Education (MSTHE), the current Ministry of Education and Science (MES), which led to profound changes in the Portuguese higher education system.

The MSTHE determined that higher education institutions could restructure their study programs according to the Bologna principles beginning in 2006/2007 or in 
one of the two following years. Full implementation was achieved by 2009. This means that up to 2009 we had a variety of cases in IHE.

For the purpose of modeling the demand of Engineering Courses in Portugal, in this study we analyzed the possible regression models for panel count data models by establishing a comparison between the estimators obtained, and then finding the most appropriate ones for our dataset.

This study is organized in 6 sections: besides the Introduction, the next section, The Portuguese Higher Education System, presents the organization of higher education both in terms of the nature of the institutions and their tutelage; section The Portuguese Higher Education System Access explains the procedures put in place to access higher education and how this works for the public and private subsystems; section Data and Descriptive Statistics describes the data used in this study based in descriptive analysis; section Statistical Analysis expounds on the explanatory variables, specifies the models used to estimate the demand of Engineering Courses in Portugal and presents the results obtained, exploring the significance of the work; finally, the last section presents the conclusions of the work and proposes suggestions for future research.

\section{The Portuguese Higher Education System}

Portugal has a binary higher education system, consisting of university and polytechnic education, each with distinct purposes that translate into specific curricular concepts, [4].

University education, guided by a constant perspective of promoting research and knowledge creation, aims at ensuring a solid scientific and cultural preparation, by providing a technical training that qualifies for the exercise of professional and cultural activities and by promoting the development of design capabilities, innovation and critical analysis.

Polytechnic education, guided by a constant perspective of applied research and development, aims at understanding and solving specific problems, at providing a solid cultural and technical level, and at developing the capacity for innovation, critical analysis and its applications in the pursuit of professional activities.

University education is offered by public and private university institutions while polytechnic education is offered by public and private non-university institutions. Private higher education institutions must be subject to the previous recognition of the Ministry of Education and Science (The higher education system also comprises a concordatary institution) [4].

Both university and polytechnic institutions confer the degree of licenciado (bachelor). In polytechnic education, the cycle of studies leading to the degree of licenciado has a duration of 3 years of students' work and 180 credits. In certain cases, namely those covered by internal legislation or by European legislation, the cycle of studies can have up to 240 credits with a normal length of up to seven or eight curricular semesters of students' work. In university education, the cycle 
of studies that lead to the degree of licenciado has from 180 to 240 credits and a normal length of six to eight curricular semesters of students' work.

Both university and polytechnic institutions confer the degree of mestre (master). The cycle of studies leading to the degree of mestre has from 90 to 120 credits and a normal length of three to four curricular semesters of students' work or, in exceptional circumstances, 60 credits and a duration of two semesters, resulting from a stable and consolidated practice in that specific field at international level.

In university education, the degree of mestre may also be conferred after an integrated cycle of studies (integrated master), with 300 to 360 credits and a normal length of 10 to 12 curricular semesters of students' work, for cases in which access to the practice of a certain professional activity depends on that length of time established by legal European Union (EU) standards or resulting from a stable practice consolidated in the EU. In this cycle of studies, the degree of licenciado is conferred to those who have obtained 180 credits corresponding to the first six semesters of work. The degree of doutor (doctor) is conferred by universities and university institutes.

This study focuses on the publicly-funded higher education system that offers engineering study programs of bachelor or integrated master, since these programs include the majority of candidates; they are also representative in terms of supply of land area and their access is regulated by the Department of Higher Education (Direç̧ão Geral do Ensino Superior- DGES).

\section{The Portuguese Higher Education System Access}

The MSTHE (MES), and more specifically the DGES, is in charge of the higher education sector and regulates access to the higher education system. Currently, access to higher education is conditioned by a system of numerus clausus, which defines the maximum number of students for each study program in both the public and private sectors. This number is defined by each institution, in fixed dates, and is subject to the approval of MES.

Numerus clausus works as a restriction on the supply side of the system, affecting the size and composition of the tertiary education sector [6]. Access to academic programs of bachelor or integrated master is done differently, whether in the public or in the private sector. Fig. 1 illustrates the organization of access to higher education at this level.

Access to higher education for the public sector is done annually through a national contest based on the students' revealed preferences in their application. The national contest has two major phases: the first one takes place in July/August and the second one in September and includes the vacancies that have not been filled in the first phase.

Each student ranks a maximum of six study program/institution pairs, from the most preferred (the first one) to the least preferred (the last one) alternative. The ensuing nationwide competition allocates the candidates based on their grade point 


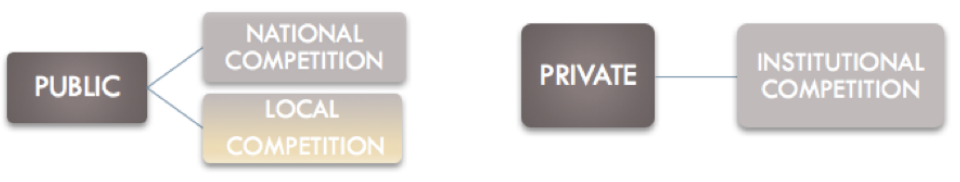

Fig. 1 Organization of higher education access.

average and the stated ranking of preferences. At each phase the applicant can only get a placement.

Students not allocated in the first phase, or allocated but not in the program/institution they want or those who had not applied in the first phase, may apply in the second phase.

\section{Data and Descriptive Statistics}

Due to differences in higher education access, most of the data available is related to the public sector disseminated by DGES according to the results of the different phases of the national contest. So, this study focuses on the publicly-funded higher education system that offers engineering study programs of bachelor or integrated master, since these programs include the majority of the candidates and they are also representative in terms of supply of land area and their access is regulated by DGES.

The data used is available online [7] and directly collected from the DGES archives. The data was collected for the period between 1997 and 2015, regarding the first phase, the most significant one, and the following variables are available:

- number of total applicants (representing the demand of pair institution/program);

- type of institution (University or Polytechnic);.

- academic program size (3 years program-Bachelor, 5 years program-Graduate, and 3+2 years program degree in two cycles - Graduate until 2006 and after 2006 the first cycle or integrated master);

- field of education and training courses (CNAEF) [8];

- number of vacancies available for pair institution/program;

- number of academic programs available for each institution;

- number of total allocated applicants in each program (total number of allocated students in pair institution/program, irrespective of their ranking);

- number of applicants by choice (1 to 6 preferences of pair institution/program);

- number of allocated applicants by choice (1 to 6 preferences of pair institution/program);

- grade point of the last place (GPLP);

- grade point average: applicants (GPAA), admission exams (GPAE), last year of secondary school, 12th year, 10th/11th year; 
- number of male applicants;

- number of female applicants;

- number of men allocated;

- number of women allocated.

In Fig. 2 we present the number of IHE by period of time: Pre Bologna period (1997-2006) and Post Bologna period (2007-2015).

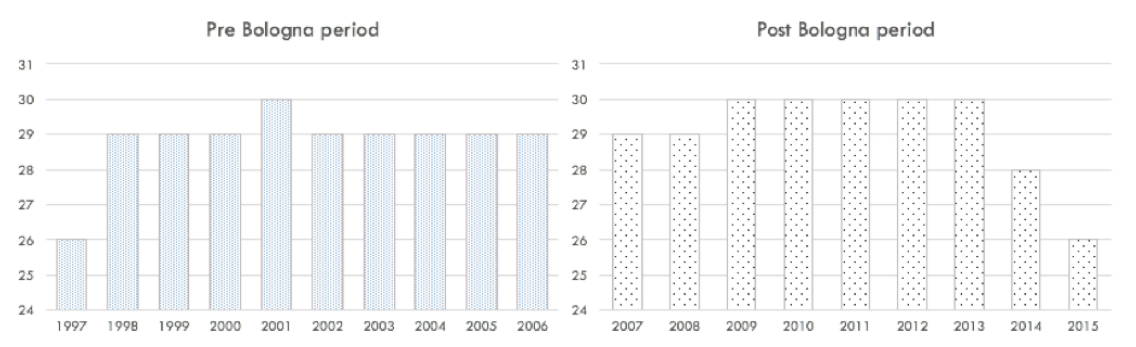

Fig. 2 Number of higher institutions

The number of IHE in both periods are similar: the minimum of IHE is 26 and the maximum is 30 , which is not the case in its variation: it has an opposite variation.

Fig. 3 and Fig. 4 represent, respectively, the total of applicants and the total of allocates for the national contest also by period.

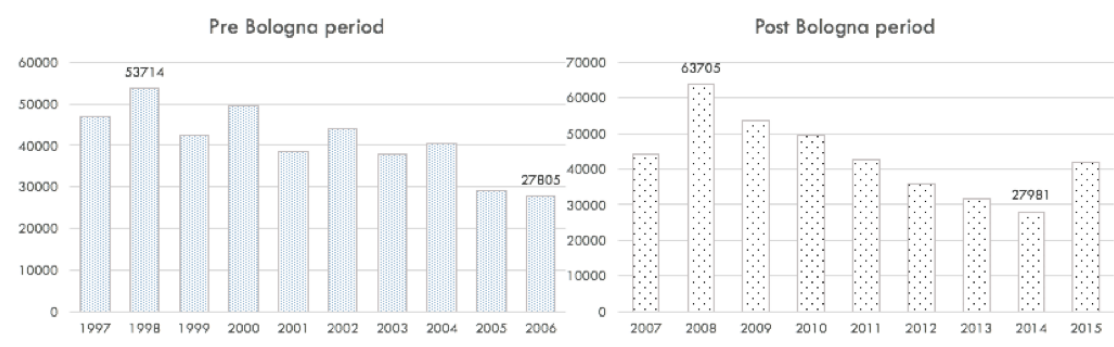

Fig. 3 Number of total applicants.

Despite the higher number of applicants in the Post Bologna period (2008), generally the number of applicants has decreased over the years.

In relation to the allocated, the maximum and minimum values have been achieved in the Post Bologna period, and the most extreme variations occurred at the end of the two periods under observation.

Fig. 5 and Fig. 6 illustrate, respectively, the number of total applicants and the number and engineering academic programs by IHE type.

To better understand the evolution of the degree (size of the program) of engineering academic programs offered over the years we present the results in Fig. 7. 

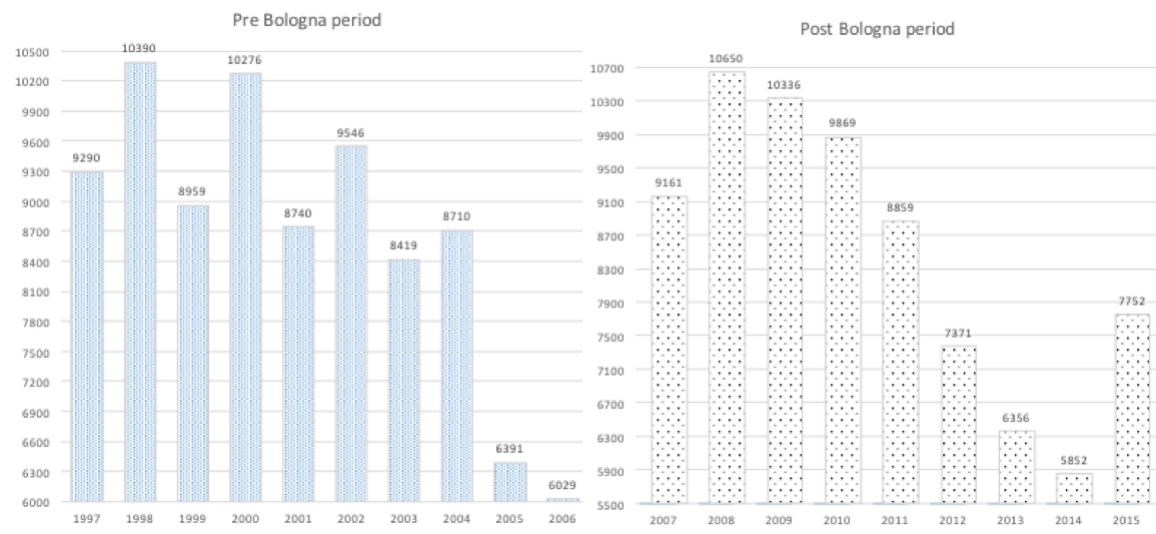

Fig. 4 Number of total allocated.
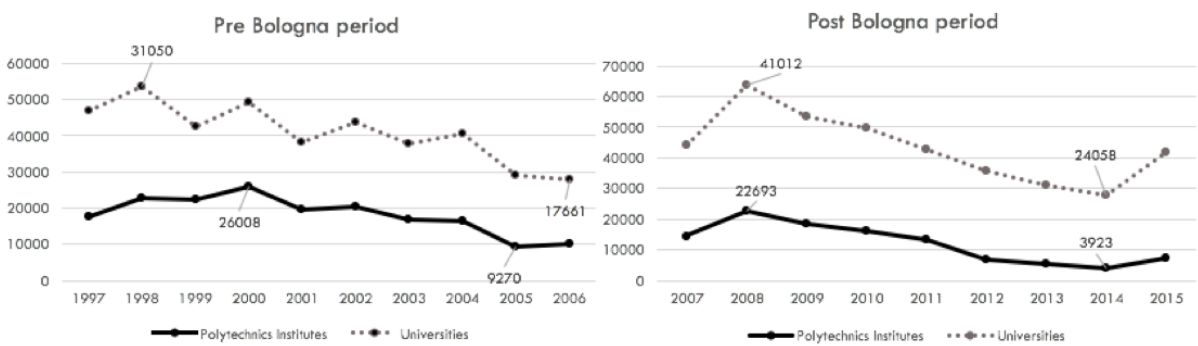

Fig. 5 Number of total applicants by IHE type.
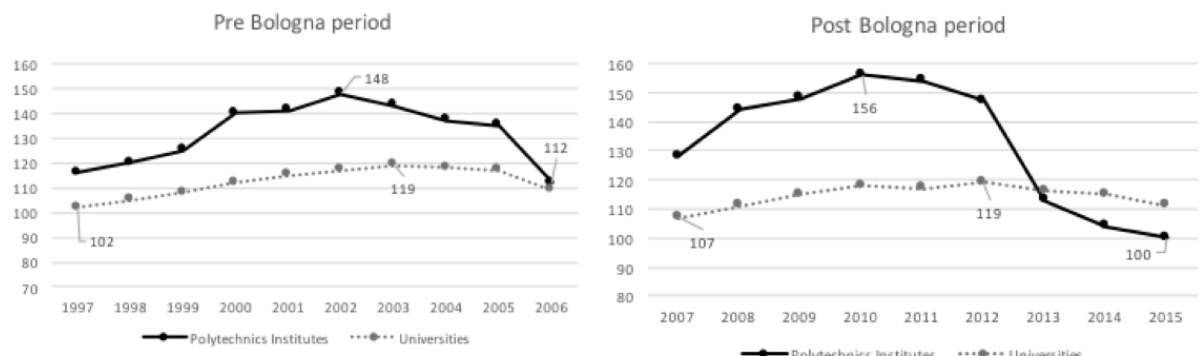

Fig. 6 Number of Engineering programs by HEI type.

In 2006 coexisted all kinds of degrees. It was a "hybrid" year because IHE could choose to start implementing the BP curricula changes in 2006 or until 2008. However, we find that with regard to Engineering academic programs the restructuring of curricula changes was complete in 2007. 


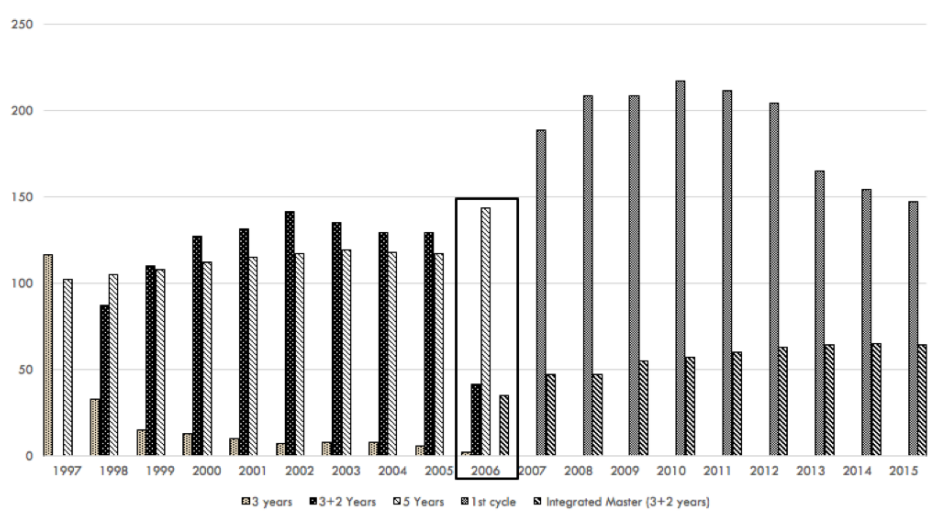

Fig. 7 Number of Engineering programs by degree.

The summary of variables-number of male applicants, number of female applicants, number of men allocated and number of women allocated-is presented in Table 1.

Table 1 Summary of variables: number of male applicants, number of female applicants, number of men allocated and number of women allocated.

\begin{tabular}{lllll}
\hline & APPLICANTS & \multicolumn{2}{l}{ ALLOCATED } \\
\hline YEARS & Male & Female & Men & Women \\
\hline 1997 & 31436 & 14140 & 6287 & 2855 \\
1998 & 36907 & 17111 & 7100 & 3187 \\
1999 & 28584 & 12848 & 5954 & 2825 \\
2000 & 32409 & 15534 & 6869 & 3404 \\
2001 & 27298 & 11802 & 5953 & 2686 \\
2002 & 30811 & 12983 & 6554 & 3009 \\
2003 & 26693 & 10962 & 5903 & 2665 \\
2004 & 29436 & 10955 & 6318 & 2393 \\
2005 & 22336 & 6692 & 4818 & 1573 \\
2006 & 20595 & 7001 & 4636 & 1553 \\
2007 & 31438 & 12277 & 6538 & 2660 \\
2008 & 44962 & 18391 & 7601 & 3049 \\
2009 & 38645 & 14589 & 7427 & 2932 \\
2010 & 35712 & 13654 & 7162 & 2716 \\
2011 & 30649 & 11798 & 6477 & 2440 \\
2012 & 25454 & 10116 & 5252 & 2068 \\
2013 & 22191 & 8991 & 4605 & 1732 \\
2014 & 20234 & 7383 & 4258 & 1554 \\
2015 & 31095 & 10692 & 5655 & 2070 \\
\hline
\end{tabular}




\section{Statistical Analysis}

Statistical analysis was performed using the SPSS statistic software and STATA statistical data analysis software. A Kolmogorov-Smirnov test was used to verify data normality ( $\mathrm{p}$-value $<0.001$ ), for which the results indicated that non-parametric tests should be used for all comparisons.

In order to analyze if the number of applicants to Engineering programs (demand) depends on the type of institution or degree (size of program), some tests were performed, Table 2 and Table 3 [9], [10].

Table 2 Mann-Whitney and Kruskal-Wallis tests for the Pre Bologna period.

\begin{tabular}{llll}
\hline \multirow{2}{*}{ Pre Bologna } & & Mann-Whitney & Kruskal-Wallis \\
\hline \multirow{2}{*}{1997} & & IHE type & Size of program \\
& test statistics & -4.068 & 16.552 \\
1998 & p-value & $<0.0001$ & $<0.0001$ \\
& test statistics & -3.245 & 20.686 \\
1999 & p-value & 0.001 & $<0.0001$ \\
& test statistics & -0.165 & 15.939 \\
2000 & p-value & $\mathbf{0 . 8 6 9}$ & $<0.0001$ \\
& test statistics & -0.346 & 11.503 \\
2001 & p-value & $\mathbf{0 . 7 2 9}$ & 0.003 \\
& test statistics & -0.331 & 7.746 \\
2002 & p-value & $\mathbf{0 . 7 4 1}$ & 0.021 \\
& test statistics & -1.397 & 8.095 \\
2003 & p-value & $\mathbf{0 . 1 6 2}$ & 0.017 \\
& test statistics & -2.229 & 10.31 \\
2004 & p-value & 0.026 & 0.006 \\
& test statistics & -3.19 & 16.367 \\
2005 & p-value & 0.001 & $<0.0001$ \\
& test statistics & -5.351 & 33.03 \\
2006 & p-value & $<0.0001$ & $<0.0001$ \\
& test statistics & -3.257 & 45.001 \\
& p-value & 0.001 & $<0.0001$ \\
\hline
\end{tabular}

The demand (number of applicants) of Engineering programs depended on the size of the programs for the two periods, but if we only consider the type of IHE then there is no dependency during the Pre Bologna period from 1999 to 2002.

\subsection{Modeling Approach}

The purpose of this study is to establish a comparison between the estimators for regression models by finding the most appropriate ones for our dataset, and so we describe the possible models to explain the number of applicants. 
Table 3 Mann-Whitney tests for the Post Bologna period.

\begin{tabular}{llll}
\hline & & Mann-Whitney & Mann-Whitney \\
\hline Post Bologna & & IHE type & Size of program \\
\hline \multirow{2}{*}{2007} & test statistics & -6.438 & -7.324 \\
& p-value & $<0.0001$ & $<0.0001$ \\
2008 & test statistics & -7.287 & -7.493 \\
& p-value & $<0.0001$ & $<0.0001$ \\
2009 & test statistics & -7.99 & -8.367 \\
& p-value & $<0.0001$ & $<0.0001$ \\
2010 & test statistics & -8.761 & -8.914 \\
& p-value & $<0.0001$ & $<0.0001$ \\
2011 & test statistics & -9.143 & -9.014 \\
& p-value & $<0.0001$ & $<0.0001$ \\
2012 & test statistics & -10.352 & -9.023 \\
& p-value & $<0.0001$ & $<0.0001$ \\
2013 & test statistics & -8.897 & -8.24 \\
& p-value & $<0.0001$ & $<0.0001$ \\
2014 & test statistics & -8.697 & -7.926 \\
& p-value & $<0.0001$ & $<0.0001$ \\
2015 & test statistics & -8.841 & -7.537 \\
& p-value & $<0.0001$ & $<0.0001$ \\
& & &
\end{tabular}

Since the response variable is a nonnegative integer and since its distribution is skewed to the left, a count data type of model is appropriate [11]. As already mentioned the data for nineteen academic years is available, and so we have a panel structure with repeated observations on the same academic program and institution, which allows controlling for study program characteristics that are not observable but are assumed constant over time.

The starting point model for count data is the Poisson regression model with the exponential mean function [11]

$$
\mu=\exp \left(\mathbf{x}^{\prime} \cdot \beta\right) .
$$

In our data, descriptive statistics show that the dependent variable presents overdispersion, so the Negative Binomial regression model might be more appropriate for the data. Since we have repeated measures in individuals $i$ over time $t$ data for $i=1, \ldots, n$ and $t=1, \ldots, T$, and $y_{i t}$ are nonnegative integer valued outcomes. So our data is in a panel structure. As established by [13], a major advantage of panel data is increased precision in estimation. This is the result of an increase in the number of observations owing to combining or pooling several time periods of data for each individual. However, for valid statistical inference one needs to control for likely correlation of regression model errors over time for a given individual. A second attraction of panel data is the possibility of consistent estimation of the fixed effects model, which allows for unobserved individual heterogeneity that may be correlated with regressors. 
Most disciplines in applied statistics treat any unobserved individual heterogeneity as being distributed independently of the regressors. Then the effects are called random effects, though a better term is purely random effects. Compared to fixed effects models, this stronger assumption has the advantage of permitting consistent estimation of all parameters, including coefficients of time invariant regressors. However, random effects and pooled estimators are inconsistent if the true model is one with fixed effects [13]. Therefore we performed the Hausman test with the null hypothesis: individual effects are uncorrelated with other regressors in the model that is the most appropriate for the data under study. We rejected the null hypothesis, meaning that we should use the fixed effects model.

Therefore, we estimated the data according to [12], following these regression models for panel count data:

1. Pooled Poisson and Negative Binomial regression models population-averaged (PPA and NBPA),

$$
y_{i t}=\alpha_{i}+\mathbf{x}_{i t}^{\prime} \beta_{i}+\mu_{i t}
$$

where $y_{i t}$ is the scalar dependent variable, $x_{i t}$ is a $k \times 1$ vector of independent variables and $u_{i t}$ is i.i.d. with mean 0 and variance $\sigma_{u}^{2}$.

2. Negative Binomial regression model with Fixed Effects (NBFE) and Random Effects (NBRE),

$$
y_{i t}=\mathbf{x}_{i t}^{\prime} \beta_{i}+\left(\alpha_{i}+\varepsilon_{i t}\right)
$$

a. Fixed effects:

$\alpha_{i}$ is a random variable possibly correlated with $\mathbf{x}_{i t}$.

b. Random effects:

$\alpha_{i}$ is purely random (usually i.i.d. $N\left(0, \sigma_{\alpha}^{2}\right)$ ) uncorrelated with $\mathbf{x}_{i t}$. Being,

i. Poisson,

$$
\operatorname{Pr}(Y=y \mid \mu)=\frac{e^{-\mu} \mu^{y}}{y !}
$$

where $y$ is the count for our dependent variable, $\mu=\exp \left(\mathbf{x}^{\prime} \cdot \beta\right)$.

ii. Negative Binomial,

$$
\operatorname{Pr}(Y=y \mid \mu, \alpha)=\frac{\Gamma\left(y+\alpha^{-1}\right)}{\Gamma(y+1) \Gamma\left(\alpha^{-1}\right)}\left(\frac{\alpha^{-1}}{\alpha^{-1}+\mu}\right)^{\alpha^{-1}}\left(\frac{\mu}{\alpha^{-1}+\mu}\right)^{y}
$$

where $y$ is the count for our dependent variable, $\mu(\mathbf{x})=\exp (\mathbf{x} \cdot \beta), \alpha \geq 0$ is the overdispersion parameter, $\Gamma($.$) is the gamma function, and \mathbf{x}$ is a vector of regressors. This form assumes constant dispersion within groups, equal to $1+\alpha \mu(\mathbf{x})$. The mean and variance of $Y$ are defined as $\mu(\mathbf{x})$ and $(1+\alpha \mu(\mathbf{x})) \mu(\mathbf{x})$, respectively.

We performed these models, the Poisson model was considered as reference, and the results are presented in Table 4.

Since we used the Poisson regression model as a starting point and since it cannot be applied because of overdispersion, we only analyzed the results from the negative 
Table 4 Results of the modeling approach.

\begin{tabular}{|c|c|c|c|c|c|c|c|c|c|}
\hline & PPA & NBPA & NBRE & NBFE & & PPA & NBPA & NBRE & NBFE \\
\hline \multirow[t]{2}{*}{ HEY type } & 0.0106 & $0.0765 * *$ & $0.1641 * * *$ & $0.1365^{* *}$ & $\begin{array}{l}\text { Allocated } \\
\text { 1st choice }\end{array}$ & $0.0029 * *$ & $0.0070 * * *$ & $0.0030 * * *$ & $0.0028 * * *$ \\
\hline & $(0.0379)$ & $(0.0344)$ & $(0.0326)$ & $(0.0504)$ & & (0.0009) & $(0.0013)$ & $(0.0006)$ & $(0.0006)$ \\
\hline \multirow[t]{2}{*}{ CNAEF } & 0.0003 & -0.0003 & 0.0001 & 0.0003 & $\begin{array}{l}\text { Allocated } \\
\text { 2nd choice }\end{array}$ & -0.0013 & $-0.006^{* * *}$ & $-0.002 * *$ & $-0.002 * *$ \\
\hline & $(0.0002)$ & $(0.0002)$ & $(.0002)$ & $(0.0002)$ & & $(0.0008)$ & $(0.0013)$ & $(0.0008)$ & $(0.0008)$ \\
\hline \multirow{2}{*}{$\begin{array}{l}\text { Size } \\
\text { Program }\end{array}$} & $-0.032 * *$ & $-0.061 * * *$ & $-0.054 * * *$ & $-0.049 * * *$ & Allocated & -0.0045 & -0.0012 & $-0.005 * *$ & $-0.004 * *$ \\
\hline & $(0.0116)$ & $(0.0123)$ & $(0.0071)$ & & 3th choice & $(0.0026)$ & $(0.0014)$ & $(0.0013)$ & $(0.0013)$ \\
\hline \multirow[t]{2}{*}{ Vacancies } & $-0.007 * * *$ & $-0.002 * *$ & $-0.005 * * *$ & $-0.006 * * *$ & $\begin{array}{l}\text { Allocated } \\
\text { 4th choice }\end{array}$ & 0.0029 & 0.0051 & 0.0028 & 0.0023 \\
\hline & $(0.0009)$ & $(0.0008)$ & $(0.0005)$ & $(0.0005)$ & & $(0.0037)$ & $(0.0034)$ & $(0.0022)$ & $(0.0022)$ \\
\hline \multirow[t]{2}{*}{ Allocated } & $0.0081 * * *$ & $0.0057 * *$ & $0.0095 * * *$ & $0.0096^{* * *}$ & $\begin{array}{l}\text { Allocated } \\
\text { 5th choice }\end{array}$ & 0.0007 & -0.0003 & -0.0007 & -0.0003 \\
\hline & $(0.0016)$ & $(0.0018)$ & (0.0009) & $(0.0009)$ & & $(0.0040)$ & $(0.0031)$ & $(0.0023)$ & $(0.0023)$ \\
\hline GPLP & $-0.002 * *$ & $-0.008 * * *$ & $-0.004 * * *$ & $-0.004 * * *$ & $\begin{array}{l}\text { Allocated } \\
\text { 6th choice }\end{array}$ & -0.0026 & -0.0013 & 0.0006 & 0.0013 \\
\hline \multirow[t]{2}{*}{ GPAA } & -0.0026 & -0.0001 & $-0.0032 * *$ & $-0.0032 * *$ & $\begin{array}{l}\text { Male } \\
\text { apllicant }\end{array}$ & 0.0001 & -0.0011 & $-0.0004 * *$ & -0.0002 \\
\hline & $(0.0023)$ & $(0.0020)$ & $(0.0013)$ & $(0.0014)$ & & $(0.0$ & $(0.0$ & $(0.0$ & $(0.0002)$ \\
\hline \multirow[t]{2}{*}{ GPAE } & -0.0015 & 0.0002 & -0.0004 & -0.0007 & $\begin{array}{l}\text { Female } \\
\text { apllicant }\end{array}$ & 0.0008 & $0.0011 * *$ & $0.0008 * * *$ & $0.0008 * * *$ \\
\hline & $(0.0010)$ & $(0.0009)$ & $(0.0007)$ & $(0.0007)$ & & $(0.0004)$ & $(0.0005)$ & $(0.0001)$ & $(0.0001)$ \\
\hline \multirow[t]{2}{*}{$\begin{array}{l}\text { Apllicants } \\
\text { 1st choice }\end{array}$} & 0.0000 & -0.0011 & $-0.0004 * *$ & -0.0002 & $\begin{array}{l}\text { Men allo- } \\
\text { cated }\end{array}$ & 0.0013 & $0.0030 * *$ & $\begin{array}{l}0.0013 \\
* * *\end{array}$ & $0.0012 * * *$ \\
\hline & $(0.0003)$ & $(0.0007)$ & $(0.0002)$ & $(0.0002)$ & & $(0.0007)$ & $(0.0009)$ & $(0.0003)$ & $(0.0003)$ \\
\hline \multirow[t]{2}{*}{$\begin{array}{l}\text { Apllicants } \\
\text { 2nd choice }\end{array}$} & 0.0008 & $0.0011 * *$ & $0.0008 * * *$ & $0.0008 * * *$ & $\begin{array}{l}\text { Women al- } \\
\text { located }\end{array}$ & 0.0007 & $0.0033 * * *$ & $0.0007 * *$ & $0.0007 * *$ \\
\hline & $(0.0004)$ & $(0.00$ & $(0.0001)$ & $(0.00$ & & $(0.0005)$ & $(0.00$ & $(0.00$ & $(0.0003)$ \\
\hline \multirow{2}{*}{$\begin{array}{l}\text { Apllicants } \\
\text { 3th choice }\end{array}$} & 0.0013 & $0.0030 * *$ & $0.0013 * * *$ & $0.0012 * * *$ & Intercept & $0.0060 * * *$ & $0.0096 * * *$ & $0.0059 * * *$ & $0.0057 * * *$ \\
\hline & $(0.0007)$ & $(0.0009)$ & $(0.00$ & $(0.00$ & & $(0.0010)$ & $(0.0012)$ & $(0.1$ & $(0.0$ \\
\hline \multirow{2}{*}{$\begin{array}{l}\text { Apllicants } \\
\text { 4th choice }\end{array}$} & 0.0007 & $0.0033 * * *$ & $0.0007 * *$ & $0.0007 * *$ & LL & & & -22444.1 & -19495.8 \\
\hline & $(0.0005)$ & $(0.0007)$ & $(0.0002)$ & $(0.0003)$ & & & & & \\
\hline \multirow{2}{*}{$\begin{array}{l}\text { Apllicants } \\
\text { 5th choice }\end{array}$} & $0.0060^{* * *}$ & 0.0096 *** & $0.0059 * * *$ & $0.0057 * * *$ & Wald & $2200.3 * * *$ & * $3397.4 * * *$ & $14433.9 * * *$ & $* 13280.5 * * *$ \\
\hline & $(0.0010)$ & $(0.0012)$ & $(0.0005)$ & $(0.0005)$ & & & & & \\
\hline \multirow{2}{*}{$\begin{array}{l}\text { Apllicants } \\
\text { 6th choice }\end{array}$} & $0.0058 * * *$ & $0.0117 * * *$ & $0.0063 * * *$ & $0.0061 * * *$ & DF & 26 & 26 & 26 & 26 \\
\hline & $(0.0008)$ & $(0.0009)$ & $(0.0005)$ & $(0.0005)$ & & & & & \\
\hline
\end{tabular}

*Standard errors in parentheses; Statistical significance: $*<.05, * *<.01, * * *<.001$

binomial regression models. As one can be see in Table 4, results can vary across models. For example, the significant predictors of the number of applicants for all the models are: IEH type, size of program, vacancies, number of allocated, grade point of the last place, number of applicants in 2nd, 3th, 4th, 5th and 6th choices, 
number of allocated in 1st and 2th choices, number of female applicant and finally the number of men and women allocated. These results indicate that the NBFE model most accurately explained the data, confirming the results obtained by the Hausman test [13].

When we performed in STATA a Negative Binomial regression model for panel count data it automatically computed a Wald test that evaluates the null hypothesis that the coefficients are equal to zero. In the presented analysis this test was statistically significant, $\mathrm{p}$-value $<0.0001$. Therefore, we could conclude that at least one coefficient differs significantly from zero.

\section{Conclusions and Future Work}

The aim of this paper was to understand the impact of the Bologna Process on the demand of Engineering courses in Portugal. Since the major changes caused by the Bologna Process were in the degrees attributed by the two types of Institution of Higher education (Universities or Polytechnics), first it was tested if the demand was influenced by these characteristics. To this end, we have performed the MannWhitney and Kruskal-Wallis tests, and found that there is a change in the behavior of the demand during the Pre Bologna (1997-2006) and Post Bologna (2007-2015) periods. Since 2007 the demand depends, without exception, on the type of degrees attributed (Graduate, Master, Doctor) or on the type of institution (Universities or Polytechnics). These results point to a behavioral change of the variable response under study (demand for Engineering courses in Portugal), showing that is effectively necessary to further deepen the study of the Bologna Process impact.

Furthermore, we have also estimated the demand during a nineteen years period (1997 to 2015) by applying the models (Pooled Poisson and Negative Binomial regression models population-averaged, Negative Binomial regression model with fixed effects and random effects) deemed more suitable for the variables under study. The results seem to indicate that the best model for our data is the Negative Binomial regression model with fixed effects.

In future work, we intend to explore this model with more explanatory variables and to evaluate the model behavior during the Pre and Post Bologna periods in order to better assess the impact of the Bologna Process.

\footnotetext{
Acknowledgements A. Manuela Gonçalves and Raquel Oliveira were supported by the Research Centre of Mathematics of the University of Minho with the Portuguese Funds from the "FCTFundação para a Ciência e a Tecnologia”, through the Project PEstOE/MAT/UI0013/2014. Rosa M. Vasconcelos was supported by the Foundation through "FCT - Fundação para a Ciência e Tecnologia", within the Project UID/MAT/00013/2013, by FEDER funds through the Competitivity Factors Operational Programme - COMPET and by national funds through FCT within the scope of the project POCI-01-0145-FEDER-007136.
} 


\section{References}

1. http://www.ehea.info/pid34248/history.html.

2. European Ministers of Education. The Bologna Declaration, 1999.

3. http://www.europa.eu.

4. http://www.dges.mctes.pt.

5. OECD, Organization for economic co-operation and Development (2006). Reviews of National policies for education: Tertiary education in Portugal. Examiner's Report. Available at http://www.dges.mctes.pt/NR/rdonlyres/8B016D34-DAAB-4B50-ADBB25AE105AEE88/2564/Backgoundreport.pdf.

6. http://www.dges.mctes.pt/DGES/pt/Estudantes/Acesso.

7. http://www.dges.mctes.pt/DGES/pt/Estudantes/Acesso/Estatisticas/.

8. http://www.dados.gov.pt/PT/CatalogoDados/Dados.aspx?name=ClassNacionaldeareasdeeducacaoeformacao.

9. Higgins, J. H. (2004). Introduction to Modern Nonparametric Statistics. Thomson, Toronto.

10. Siegel, S., \& Castellan, N. J. (1988). Nonparametric Statistics for the Behavioral Sciences. McGraw-Hill, Second Edition.

11. Cameron, A. C., \& Trivedi, P. K. (1998). Regression analysis of count data. Cambridge: Cambridge University Press.

12. Cameron, A. C., \& Trivedi, P. K. (2009). Microeconometrics Using Stata. Stata Press.

13. Cameron, A. C., \& Trivedi, P. K. (2010). Microeconometrics: Methods and Applications. Stata Press. 